\title{
LA EXPERIENCIA DEL PARTIDO DOS TRABALHADORES EN LA ALCADÍA DE SAO PAULO *
}

\author{
Lucio Kowarick y André Singer **
}

\section{INTRODUCCIÓN}

"Todo esto, por tanto, me hizo comprender que los trabajadores necesitaban organizarse políticamente..." ! Con esta idea, Lula, por aquel entonces presidente del sindicato de los metalúrgicos de Sao Bernardo e Diadema, después de las masivas y prolongadas huelgas que se producen a partir de 1978, muestra los límites de las luchas sindicales para garantizar las conquistas del movimiento obrero. En esta frase está contenido el empeño de construir una organización esencialmente política de defensa de las clases trabajadoras.

Queda claro hasta donde pueden llegar los conflictos fabriles. Como mucho, mejoran las condiciones de trabajo y aumentan la autonomía obrera. Difícilmente alcanzan dimensiones más amplias, tanto en el ámbito regional como en aglutinar otras categorías de asalariados. Sin duda tienen contenidos y consecuencias políticas pero, en cuanto meros conflictos, las luchas laborales nos conducen a la ampliación de derechos y a la consolidación de la ciudadanía: los movimientos sociales tienden a ser locales, corporativos y parciales. Por más amplios y generales que sean, son las instancias propiamente políticas, el poder del Estado y los partidos políticos, los que pueden llevar a una mayor universalización, en términos de aglutinación y de representación de los muchos y variados intereses inherentes a una sociedad marcada por una amplia desigualdad.

No se trata sólo de representar al proletariado fabril, sino también a las amplias y múltiples categorías de trabajadores del campo y de la ciudad; a éstas el discurso y la práctica partidaria petista, a lo largo de los años 80 , adiciona incluso a sectores de las camadas medias.

En la senda de la reforma en la legislación partidaria 1979, impuesta por el régimen militar y que acabó con el bipartidismo polarizado entre ARENA y MDB, el PT surge oficialmente en febrero de 1980. Desde sus orígenes, contó con un significativo apoyo de intelectuales, artistas, profesionales liberales así como de líderes forjados en las luchas sindicales y urbanas. Pocos son los parlamentarios que ingresaron en el PT en el momento de su creación y varios son los grupos y orientaciones ideológicas en él presentes: están los católicos que beben en las aguas de la teología de la liberación, socialdemócratas radicales y grupos que siguen la tradición marxista-leninista. Algunos tienen relación con las diversas versiones trotskistas y hasta maoístas y muchos son ideológicamente eclécticos. Otros recorren las mezclas revolucionarias temperadas por la experiencia guerrillera. Es fuerte la presencia de los grupos disidentes del Partidos Comunista Brasileiro, como también de un ideario socialista no-comunista y antisoviético, pero no anticubano, frecuentemente marcado por una visión instrumental de las instituciones políticas y de la propia democracia. No en vano, imperaba la doble militancia y hasta hoy es común la existencia de duros conflictos entre las diversas tendencias y grupos presentes en el $\mathrm{PT}^{2}$.

Sería necesario un capítulo aparte para discutir el tema de la democracia interna y la composición interna del PT. Para exponerlo de forma sumaria, el PT es un partido en el que prevalece una apertura hacia las "bases" significativamente mayor que en cualquier otra agremiación política, incluso aunque esté ocurriendo un intenso proceso de burocratización y oligarquización. Es en el interior de esta doble caracterización donde el PT tiene que ser comprendido, inclusive si lo consideramos como una experiencia en curso.

En el origen de ese complejo proceso, que contiene democracia y oligarquización -más allá de la tendencia burocratizante de cualquier organización-, se encuentran algunos factores peculiares al PT. El primero es haber nacido sobre una fuerte retórica basista que, como se sabe, cobra su precio en la práctica, a pesar de ser, en principio, sólo en el discurso.

Traducción: Ariel Jerez.

* Título original del artículo: "A Experiencia do Partido dos Trabalhadores na Prefeirura de Sao Paulo".

** Lucio Kowarick y André Singer son profesores en el Departamento de Ciencia Política de la Universidad de Sao Paulo (DCP-USP)

1. L. I. Silva (Lula): Entrevistas e Discursos. (Sao Bernardo do Campo: ABCD Sociedade Cultural), 1980.

2. En 1991 había 16 tendencias políticas en el PT. En esta época, la mayoría de ellas ya había abandonado la doble militancia y aceptado las resoluciones del V Encuentro Nacional realizado en 1987 en la que se reglamentó su actuación. Ver C.B. Azevedo: "Leninismo e Social Democracia: Uma investigaçao sobre o projeto do partido dos trabalhadores", Tesis de Maestrado, Departamento de Ciencia Política, Universidades de Sao Paulo, 1991 
En segundo lugar, la existencia de tendencias políticas organizadas en el interior del partido desde el inicio tiene dos efectos. Por un lado, obligó a muchos de los que querían participar a organizarse en alguna forma de organismo para-partidario, cuestión que limitó la participación de los no-organizados. Por otro, trajo consigo una disputa interna que impidió la consolidación de una corriente hegemónica capaz de controlar las instancias decisorias. Con todo esto, el partido muchas veces se abría o era forzado a abrirse a la posibilidad de participación de los militantes de base en decisiones cruciales.

El resultado es que hoy, a pesar de estar garantizada la presencia de las tendencias minoritarias en los órganos de decisión del partido, de que los militantes de base tengan voz en los directorios* y en la prensa partidaria para estimular el debate y garantizar la libertad de expresión de las tendencias, hay no sólo una intensa disputa para ocupar cargos en la jerarquía del partido, sino que también esta cuestión es usada en beneficio de personas y grupos.

Vale la pena conceder la palabra a los militantes: "Los capas pretas con los dirigentes partidarios que tienen mucho poder personal... Ninguna gran decisión se logra sin ellos. Ellos son los que negocian por las tendencias". $\mathrm{O}$ incluso: "Si se hace un mapeamiento del movimiento popular... algunas áreas son aparatos de determinada corriente partidaria (...). El problema es que existen dueños del movimiento. Es un corral (*) de la tendencia(...). Si tengo un movimiento $\mathrm{x}$, significa que tengo $\mathrm{x}$ tanques, $\mathrm{x}$ tanques significa que yo gano el directorio, ganar el directorio significa que mi tendencia tendrá más fuerza en el directorio municipal, en el directorio regional" 3 .

Es importante destacar que esa pluralidad, muchas veces sectaria y antagónica, conlleva una enorme riqueza en experiencias, inédita en la historia política brasileña: se trata de un partido, con gran número de militantes que, en los años 80 , ayudó a construir movimientos sindicales y populares y al mismo tiempo fue construido por ellos ${ }^{4}$.

A medida que estos procesos acontecían, el PT se consolidaba como organización de masas y desarrollaba ciertos mecanismos democráticos de participación interna. Priorizaba tanto el enraizamiento en los movimientos sociales como la accción político-electoral y la conquista de cargos parlamentarios y ejecutivos, a la vez que pasa a enfrentar, de forma creciente, la democracia como valor universal de sistema de gobierno: el ideario socialista continua siendo el horizonte político-ideológico del Partido, pero la vía insurreccional es radicalmente substituida por una concepción que privilegia los conflictos y debates institucionales.

Sin embargo, no era así en 1982, cuando con posterioridad al golpe militar se producen las primeras elecciones directas para gobernador del Estado y el PT las disputa; era su debut electoral, teniendo a Lula como candidato al gobierno del Estado de Sao Paulo. En éstas Lula comenta: "Las elecciones (constituyen) (...) un episodio, un momento definido de nuestra actividad permanente, en busca de construir una sociedad socialista, sin explotadores ni explotados" 5 . Es decir, elecciones como táctica para construir un poder popular para alcanzar el socialismo: las plataformas de la campaña denotaban no sólo una concepción instrumental de la democracia, sino la idea que presenta a la política como algo sospechoso y al poder algo muy sucio. El PT de la época radicaliza una visión dicotómica y polarizada de la sociedad brasileña, expresa en los slogans "Vote 3, el resto es burgués" o "Trabajador vota en trabajador", distanciándose de esta manera de un discurso que incorporase las aspiraciones e intereses de las clases medias ${ }^{6}:$ "Para la clase trabajadora -dice Lula- democracia significa barriga llena..." ?

Se trataba más de incitar el conflicto de clases a través de una concepción estrecha y rígida del antagonismo entre dominantes y dominados que de ampliar los derechos básicos de ciudadanía. O mejor dicho: éstos sólo interesan en la medida en que sirven para despertar la conciencia de los trabajadores y construir un poder popular alternativo al orden capitalista.

En esta dirección caminan las palabras de los "compañeros-candidatos". Beben en las fuentes del obrerismo radical, combinado con un basismo que valoriza los "saberes y fazeres" del pueblo y que, siendo así, descalifica otra condición que no sea la del aprendizaje realizado por medio de la experiencia del explotado y del oprimido. Figuras sesudas y sufridas, en los rápidos momentos que aparecen en los espacios publicitarios gratuitos de televisión, resaltan la condición de obrero y campesino, el hecho de tener la educación primaria incompleta o ser vecinos de las favelas y, siempre que es posible, destacan el exilio, la tortura y la prisión, a lo que Lula añade: "Es poner a la clase trabajadora (...). En cada barrio sería construida una asamblea, escogido un Consejo Popular. Cada actitud del gobierno, en la aprobación del presupuesto o en la consecución de una obra popular, tendría que realizarse por consulta popular..." ${ }^{8}$.

La acción política refleja el nuevo movimiento sindical y popular, la dureza de las huelgas obreras, los embates procedentes de las reivindicaciones urbanas, la esperanza de liberación de las comunidades eclesiales de base,

* Directorios son los órganos ejecutivos del partido que corresponden con las diferentes divisiones administrativas del territorio nacional. En el texto se han conservado también los términos PrefeituraPrefeita (ayuntamiento-alcaldía) y veeadores (concejales), así como estadual, que hace referencia al estado como parte de la federación, por lo que podría ser entendido como provincial, y en el caso español, como autonómico. Por otra parte se incorporan como neologismos los vocablos militantismo, principismo-principista y asambleísmo por considerarlos expresivos de la realidad que se está analizando ( $\mathrm{N}$ del T.).

** El término corral, inicialmente se refiere al proceso electoral para indicar una situación de voto cautivo; aquí hace referencia a un espacio, ya sea urbano o rural, que tiene su relación en los poderes públicos -en este caso las instancias partidarias- mediatizada por una organización que tiene poder para instrumentalizar esa relación en su provecho ( $\mathrm{N}$. del T.).

3. Entrevistas realizadas en 1990 entre militantes del PT (un técnico que ocupaba un alto cargo en la Administración Erundina y un asesor de la Cámara Municipal). A pesar de todo esto y mucho más, nuestra opinión nos lleva a optar por la visión según la cual "no hay duda de que el grado de democracia interna y el de cualquier otro partido importante en Brasil”. Ver M.E. Keck: A Lógica da diferencia: O Partido dos Trabalhadores na Construçao da Democracia. 9 Sao Paulo: Ed. Atica, 1991).

4. M. Keck, op cit, p.146.

5. Jornal dos Trabalhadores - Carta Eleitoral, 21 de abril, 1982, p. 3.

6. Ver R. Meneguello: PT: A Formaçao de um partido. (Sao Paulo: Paz e Terra, 1989).

7. Ver Folha de Sao Paulo, 15/11/1982.

8. Idem 
la amargura e innovaciones de las izquierdas dispersas y destrozadas por la represión". El "militarismo" de esta concepción no se generaliza políticamente, pures no adiciona la singularidad de éste o aquel grupo con su modo de vida y de trabajo específico y sus dispares trayectorias de reivindicación.

El relativo fracaso en las elecciones de 1982 hace que los militantes sobrevaloren, en un primer momento, las luchas sindicales y populares en detrimento de la acción político-institucional. Pero en el movimiento de las Dietas Ja! de 1984, en el cual, por lo menos en Sao Paulo, el PT tuvo un papel fundamental, resitúa la cuestión política nacional en nuevos términos: se trata de la elección directa de un Presidente de la República. Debido al fracaso de este esfuerzo y la consiguiente elección indirecta realizada por el Colegio Electoral, el PT es el único partido que no participa de la votación, denunciando las componendas de la transición realizada en un cerrado pacto inter-élites. Acusado de principista y sectario, el Partido es marginado, aunque esta situación se iría revirtiendo a lo largo de los 80 . Su gran rédito político será el haber sido el único opositor legítimo de la Nova República, principalmente después del fracaso del Plan Cruzado en 1986.

Pero antes de esto, ya el PT se presenta con nueva cara en las elecciones municipales de Sao Paulo en 1985. Los candidatos, inclusive al cargo ejecutivo, muestran un perfil más volcado en los patrones de confianza que caracterizan las expectativas de camadas medias. Las plataformas de campaña son más amplias y el programa en la televisión es creativo y, sobre todo, bienhumorado. No se trata más de privilegiar al obrero industrial, al campesinado y al asalariado rural, sino de construir un discurso que incorpore a los vastos y variados segmentos de trabajadores del sector terciario, ya por aquel entonces víctimas de la compresión salarial y en situación de colonización de sus respectivas categorías sindicales." ... El fracaso de un discurso electoral de base clasista en 1982 produjo, a partir de 1985, una disposición para realizar un llamamiento partidario hacia un electorado más amplio (...). En este contexto más amplio el discurso sobre la ciudadanía y el del acceso al poder, que en 1982 había sido subsumido en el discurso de clase, gana vida propia ${ }^{10}$.

De 1982 en adelante aumenta el número de parlamentarios petistas en las Asambleas Legislativas estaduales y en la Cámara de Diputados. La tabla I muestra que el partido dejó de ser un fenómeno exclusivamente paulista. En las elecciones de 1988, el PT no sólo conquistó el Ayuntamiento de Sao Paulo sino que también venció en importantes ciudades del estado como Sao Bernardo do campo, Santo André, Diadema, Campinas, Piracicaba y Santos, además de conquistar las capitales de los estados de Río Grande do Sul y Espirito Santo".

La victoria en estos ayuntamientos conlleva nuevos horizontes y nuevos desafíos para el partido. De su énfasis en el movimiento social, el PT pasa a valorar también la lucha parlamentaria, fundamentalmente después de 1986, con ocasión de las elecciones para la Asamblea nacional Constituyente*. En una tercera fase, dos años después, tiene inicio la experiencia de administrar ciudades enormes, con gigantescos problemas. Antes de ahondar en este proceso haciendo referencia a la ciudad de Sao Paulo, conviene, nuevamente, utilizar un discurso de Lula para destacar los cambios acaecidos en las plataformas electorales y, la última instancia, las transformaciones del propio PT. Durante el V Encuentro Nacional en 1987 él declara: "En 1982, cuando fui candidato a Gobernador de São Paulo, cometí un gran error. Ustedes recuerdan que la propaganda del PT, en la que los menos peligrosos estaban condenados a noventa años de cárcel. Hicimos un discurso en el que yo decía: Lula, candidato a gobernador número 3, ex-tintorero, ex-tornero mecánico, ex-sindicalista, ex-preso, ex- no sé que. Un brasileño igualito a usted. Nadie quería ser un brasileño igual a mí. Ellos querían ser un brasileño con mejores condiciones de vida, con mejor formación intelectual, con mejor calidad de vida ${ }^{12}$.

\section{LOS SABERES Y FEZERES DEL PUEBLO}

Electa Prefeita de la ciudad de Sao Paulo, con el $30 \%$ de los votos, al día siguiente de la victoria, Luiza Erundina respondería "sí" cuando se le preguntó sobre su intención de estatalizar el sistema de transporte municipal. Afirmó también que la ocupación de tierras se sitúa por encima del derecho de propiedad: "exactamente, porque es un derecho de sobrevivencia" ${ }^{13}$.

Apoyada por las tendencias internas del PT entonces denominadas "Poder Popular e Socialismo", "PT na Capital” y por varios grupos Troskistas, con amplio enraizamiento en las bases, Erundina es candidata a la Prefectura. Derrota, así, en un episodio típicamente petista, el nombre indicado por "Articulaçao" (Plinio de Arruda Sampaio) fuerza hegemónica en los órganos de dirección municipal, estadual y federal del partido, en torno de los cuales se aglutina la mayor parte de vereadores y diputados tanto estaduales como federales.

Este hecho fue interpretado como una victoria de las bases del partido y de las tendencias minoritarias y más radicales. Se trataba de una militante bastante peculiar que

* La Asamblea Nacional Constituyente, de carácter congresual y no exclusivo como solicitaron los partidos de izquierda, constituyó un escenario en el que las fuerzas políticas usan todos sus recursos para influir en el orden jurídico que se está creando. En este sentido, el PT será, gracias a su poder de movilización manifestado anteriormente en la campaña de la Diretas Ja! el más importante articulador de las demandas de los movimientos populares dentro del Congreso, con sólo 6 diputados. (N. del T.).

9. Ver Eder Sader: Cuando Novos Personagem entram em Cena. Experiencias y Lutas dos Trabalhadores da Grande Sao Paulo, (Sao Paulo: Paz e Terra, 1988).

10. M. Keck, op. cit, pag. 192. En otros términos: estaba en formación ...." aquello que se puede denominar un nuevo bloque de clase de los trabajadores, que busca unificar, en la diversidad, intereses que son más amplios de aquellos que dicen respecto a cada clase o segmento social". Documento de trabajo "Classes Socias e Projeto Político. O Partido dos Trabalhadores en Questao” (Sao Paulo: CEDEC Informaciones, marzo, 1992).

11. Estos municipios concentraban el $29 \%$ del total de la transformación industrial realizada en Brasil en 1985.

12. Ver PT-Boletim Nacional, n³3, Sao Paulo, 1987-1988

13. Entrevista a Luiza Erundina en la Folha de Sao Paulo, $16 / 11 / 1988$. 
ganaba las elecciones internas, y después las municipales: mujer y nordestina*, con larga experiencia junto a los movimientos populares -principalmente en aquellos que se aglutinan en torno a las luchas por la tierra y viviendaErundina había sido electa vereadora en 1982 y cuatro años después, diputada estadual. Buena parte de sus votos venía de estos segmentos populares y su acción parlamentaria fue en gran medida desarrollada en los barrios pobres de la periferia de Sao Paulo.

Su presencia era constante en las asambleas populares de protesta y reivindicación, campamentos e invasiones de tierras o viviendas: su lenguaje fue siempre directo y radical, y su actuación estimuló la acción de múltiples grupos de vecinos que se enfrentaban con los gobiernos estaduales y municipales a lo largo de los años 70 y 80. Debido a la trayectoria política de Elundina y a la victoria de las tendencias minoritarias, parcelas importantes de la máquina del partido y poderosos sectores y personalidades del PT sólo la apoyarían cuando se vislumbró la posibilidad de victoria, en los días finales de campaña. Asesores del partido recuerdan que..." una parte importante del 'articulaçao' no entró en la campaña (...). Los Gabinetes en la Asamblea (Legislativa) no liberaron gente para trabajar en la campaña. (...) solo en el último mes, en las últimas tres semanas" .. ${ }^{14}$. Nosotros también apuntamos: en la noche del 15 de noviembre de 1988, en plena fiesta popular en la Avenida Paulista, pocas eran las personalidades del partido que compartían la alegría de la victoria ${ }^{15}$

Este hecho no podía dejar de tener consecuencias políticas. Repercutió al menos en la organización inicial del secretariado y en la ocupación de cargos estratégicos para el funcionamiento de la máquina administrativa.

La relación de la administración con el PT estuvo marcada por sucesivas y obstinadas discordancias en cuanto a los prioridades del gobierno y la propia autonomía del Ejecutivo: la geografía política de la gestión Erundina no correspondía a la correlación de fuerzas del partido y esa relación inclusive con la mayoría de los catorce vereadores electos por el PT, frecuentemente fue tensa y algunas veces de férrea crítica y oposición ${ }^{16}$. Se debe señalar, en este sentido, la creación en 1990 del Conselho Político. Se trata de un organismo consultivo que se reúne regularmente, en el cual tienen asiento la Prefeita, algunos secretarios y vereadores, representantes de la ejecutiva municipal partidaria y de la secretaría de asuntos institucionales del PT, que procura encauzar soluciones para los problemas rutinarios de la administración.

Sin sombra de duda, el Conselho Político representó un primer paso en la maduración de las relaciones entre poder ejecutivo y el partido pues permitió disminuir las divergencias políticas y definir sus campos específicos de actuación y autonomía. A pesar de ello, como se verá en el final del capítulo, sólo fue posible debatir y encaminar soluciones para la crisis más profundas cuando, con esta finalidad, se convocó una Plenaria realizada en 1991. A partir de ahí se definió el carácter estratégico de la gestión del municipio de Sao Paulo y, como consecuencia, se creó un fórum de negociación con mayor representación de las instancias estadual y federal del partido.
Pero no siempre fue así. El mayor aislamiento político que sufriría la gestión Erundina ocurrió durante el primer año de gobierno, antes y después de las elecciones presidenciales de 1989. La calamitosa herencia de la gestión de Janio Quadros y las indecisiones de los primeros tiempos -que serán analizados a continuación-, se superpone un pesado boicot de los gobiernos estadual y federal. El intento de las demás fuerzas políticas y de los grandes grupos económicos era paralizar la administración petista, pues si el gobierno de Sao Paulo era exitoso, grandes podrían ser las posibilidades de Lula para ser electo presidente de la República. A esto, se añade la vigilancia que buena parte de la prensa hablada y escrita ejerció sobre el gobierno del PT: basura, limpieza, venta ambulante, pavimentación deteriorada en las calles, ocupación de tierras y posiciones "incendiarias" de la Prefeita, eran titulares recurrentes.

No por casualidad, las elecciones presidenciales fueron perdidas debido al voto del electorado paulistano y no por casualidad también, durante la campaña presidencial, la administración petista fue objeto de corrosivas acusaciones. Se desatan, en este sentido, los ataques acaecidos con ocasión del desmoronamiento de la favela Nova República y la muerte de algunos de sus vecinos. La dimisión sumaria, esta sí, duramente criticada por vastos sectores del PT, del secretario de negocios extraordinarios, también viceprefeito, a partir de denuncias de corrupción hasta hoy nunca probadas. Y como si fuese poco: en la margura de la derrota de Lula, el directorio municipal del partido de Sao Paulo apunta sus baterías contra Prefeitura.

Cara a la importancia de la coyuntura nacional, la administración Erundina es públicamente acusada de ocuparse sólo de "acomodar la casa" permaneciendo en una posición "defensiva”, sin tener "nada que decir ni mostrar", "acomodada”, y "tecnicista” en una cierta "parálisis”. En fin, la Prefeitura estaría siendo contaminada por un cierto administrativismo ${ }^{17}$.

El nordeste brasileño es la zona más subdesarrollada del país, por su estructura latifundista, y por tanto región que expulsa población que al llegar a las ciudades del centro-sur son víctimas de los tópicos xenófobos y racistas que, lamentablemente, se aplican a los emigrantes pobres de todo el mundo (N. del T.).

14. Entrevista realizada en 1990 con un ex-asesor parlamentario del PT.

15. La misma observación:... "Los órganos de dirección del partido no participaban de esa euforia”. M. Keck, op.cit., p.261.

16. En octubre de 1990, de los 17 secretarios de la administración petista, dos eran de la "vertiente Socialista" (antes "Poder Popular e Socialismo"), dos del PT vivo (antes "PT na Capital") y ocho eran independientes. De los cinco pertenecientes a "Articulaçao", la mayoría eran intelectuales sin fuerza decisiva en las estructuras del partido, de los administradores regionales, 6 eran de "Articulaçao" y 7 de "vertiente Socialista", mientras que los 6 restantes eran de otras tendencias. Ver C.P Bocchi y I.V. Camargo: "Os Movimentos Sociais de Sao Paulo", mimeo, Depatamento de Ciencia Política, Universidade de Sao Paulo,1990.

17. "Entendemos el administrivismo" como la política de acomodamiento con el poder económico y político establecido en la sociedad y con los intereses privados incrustados en el propio aparato burocrático. Presupone que es posible gobernar a todos desde la perspectiva de la clase trabajadora, amén de suponer la neutralidad de la máquina gubernamental. Esta versión sobredimensiona los aspectos técnicos y jurídicos de la gestión pública y secundariza los aspectos políticos que deberían estar en el centro de nuestra acción. Al mismo tiempo produce el cierre del debate político por parte de la administración y lo sustituye por la búsqueda de soluciones técnicas para el ecuacionamiento de los problemas de la ciudad". Ver Directorio Municipal PT- Sao Paulo: "Avaliaçao do $1^{\circ}$ Ano da Administraçao Petista em Sao Paulo", mimeo S.P. 17/01/1990. 
Este fue, sin duda, el momento más crítico de la administración petista, cuando no pocos creyeron que estaba en marcha una ruptura que podría ser definitiva, como ocurrió en otras prefeituras del PT.

Pero esta decisión no ocurrió en Sao Paulo. Al contrario, como se verá al final del capítulo, parece posible afirmar que, con marchas y contramarchas, Ejecutivo y partido consiguieron producir relaciones de mutuo fortalecimiento.

Conviene regresar en el tiempo, al momento de la plataforma de la campaña. La coalición que apoyo la candidatura de Erundina, que englobaba a los dos partidos comunistas, se definía por la estatización de los transportes públicos, del sistema de salud y la formación de Conselhos Populares. Priorizaba el uso social de la propiedad urbana y la no negociación con los intereses económicos: "Colocar en las manos del pueblo el gobierno de nuestra ciudad" ${ }^{18}$.

A pesar de esto, la propaganda gratuita en la televisión, reeditando el estilo de 1985 , fue crítica, creativa y bienhumorada. El discurso contenía una radicalidad de oposición a la crisis económica y social y a la transición política elitista y excluyente de la Nova República. El PT se abría por esta vía a nuevos universo que incorporaban aspiraciones, frustraciones e intereses de varias y vastas camadas sociales, inclusive las clases medias.

Hay que recordar, en este sentido, que la amplia victoria electoral del PMDB en 1986, se basó en las esperanzas depositadas en el Plan Cruzado. Con posterioridad a su rotundo y previsible fracaso, el PT se transformó para la opinión pública en el principal opositor al gobierno de Sarney. Esto porque la fuerza del PDT se limita a Río de Janeiro y los partidos gubernamentales se desgastaron en políticas palaciegas y en los favoritismo ministeriales, conviviendo con lo más fisiológico $(*)$ de la política brasileña, en medio de la inflación y la ingobernabilidad creciente, que solaparon el soporte de la transición elitista que originó la Nova República.

Después de 1986, durante el período de la Asamblea Nacional Constituyente, el PT, sumergido en los movimientos sindicales y populares, pasa a desarrollar una intensa actividad parlamentaria. Frente a los demás partidos, tiene una línea ideológica más cohesionada y coherente, al mismo tiempo que pasa a estimular y organizar la participación de expresivos segmentos sociales en torno a las demandas populares. Representante ejemplar de oposición al gobierno federal, estadual y municipal, cada vez más es visto como un agrupamiento político que no sólo critica y se opone sino que es capaz de construir. Vastos sectores de opinión pública empiezan a vislumbrar en las plataformas del PT un mensaje que muestra un proyecto alternativo.

En este cuadro de descontento generalizado, Luiza Erundina, más que otro liderazgo, también pasa a simbolizar la posibilidad de renovación en la primera disputa electoral realizada con posterioridad al desastre económico de 1986. En una ascensión vertiginosa e inesperada, en las últimas tres semanas de campaña, el PT alcanza el 30\% de los votos, aumentando significativamente la cantidad recibida de las elecciones anteriores en la ciudad de Sao Paulo: 5\% en 1982, 2\% en 1985 y apenas el 11\% en 1986.
"La sorpresa de la victoria de Sao Paulo parece tener, entre otras muchas explicaciones: la conducta coherente del partido en la defensa del programa político democrático claro y la decepción de buena parte de la población con los gobiernos estadual y federal de la Nova República. Preguntan sobre las principales razones que llevan a votar al PT el 5 de noviembre de 1988, el electorado señaló el deseo del cambio, por entender que el PT representa una nueva experiencia, y la identidad/simpatía hacia el programa e ideología petista ${ }^{19}$.

La herencia de la gestión anterior no era nada estimulante: un billón de dólares en deuda, 315 millones de dólares de pagos atrasados en el corto plazo, obras de gran porte inacabadas y de dudosa finalidad social, edificios y equipamentos deteriorados, autobuses en pésimo estado. Como si todo esto no bastase, hay que añadir el ya mencionado boicot federal, las críticas de las mass media y el desquite de los vereadores de la oposición hacia la nueva administración, pues a final de cuentas, los petistas, y en particular la vereadora y diputada Luiza Erundina, habían hecho la vida imposible de los anteriores prefeitos Reynaldo de Barros, Mario Covas y Janio Quadros.

Partido para ser oposición y no para ser gobierno, los primeros meses fueron los tiempos de los principios que se traducian en asambleas interminables, retóricas y paralizantes $^{20}$. El "principismo" (ideológico) más arraigado tal vez haya sido aquel que valoraba los saberes y fazeres (conocimientos y prácticas) del pueblo: de los Conselhos Populares deberían salir no sólo la legitimidad y la fuerza del gobierno sino también las prioridades sociales y políticas de la administración.

El modelo se basaba en los Conselhos de saúde (salud) que esparcidos en alrededor de 80 barrios de la ciudad, elegian representantes y tenían una larga tradición de lucha y organización $^{21}$

Se trataba de fomentar un poder no sólo popular sino también paralelo y alternativo, apoyado en las iniciativas de

Este vocablo propio del análisis político brasileño alude al com portamiento perverso de las instituciones que, dadas unas históricas relaciones clientelísticas y patrimonialistas de políticos y de administradores profesionales, se encuentra natural y "fisiológicamente" enquistado en la vida política, siendo un dato a considerar en cualquier cálculo político.

18. Manifiesto de Campaña 1988.

19. R. Meneguello, op. cit, p. 202.

20. Esta descripción es tomada de la entrevista de R. Rolnick: "El principio de democratización de la gestión se acabó traduciendo en 'asambleísmo', en sesiones plenarias y en una serie de reuniones interminables que acababan de paralizar todo, no dejando que las cosas fuesen implementadas y efectivamente no democratizando". Ver "Governar Sao Paulo: Primeiros Passos da Gastao Luiza Erundina”, en Entrevistas á Prefeita, n 45, 1990, p.21.

21. Los Conselhos de Saúde fueron largamente influenciados y hasta organizados por la corriente petista "Poder popular e Socialismo", con el destacado liderazgo de Eduardo Jorge, médico-sanitarista, secretario de salud de los dos primeros años de Gobierno de Erundina y hoy diputado federal. Para tener una imagen del ideario de esta tendencia vale la pena citar su tesis presentada en el VII Encuentro Nacional del PT (1990): "Un amplio movimiento de masas que sea capaz de convocar la desovediencia civil a gran escala, organizar la auto-defensa y prepararse para la confrontación táctica contra el orden jurídico-estatal vigente (...) tendrá que estar basada en esa red de organismos extra-institucionales capaces de intervenir en la sociedad política”. Ver C. Azevedo, op. cit., p. 210. 
los movimientos sociales. Por eso el esfuerzo de la administración en incentivar el surgimiento de núcleos semejantes en el área de vivienda y educación principalmente. No se trataba de mera descentralización administrativa sino una concepción de la democracia que se basaba en la participación directa de la población. Audiencias y plenos populares, discusión con los movimientos populares acerca del presupuesto de la ciudad pasaron a ser iniciativas frecuentes. Es en esta dirección que se debe entender la creación de los núcleos regionales de planificación, en los cuales, hasta 1991, cuando fueron desechados, la Administración procuró implementar políticas para los problemas que fuesen percibidos como cruciales por las camadas pauperizadas de Sao Paulo.

Sin embargo, la euforia de la participación popular en la definición de los destinos de la ciudad, están los enormes problemas que se acumulan, la necesidad de agilidad, rapidez y eficiencia en contraste con la constatación de que los movimientos son lentos, oscilantes y desiguales. Todavía más: ellos constituyen una minoría cuantitavamente irrisoria de población y, más allá de esto, no universalizan ni aglutinan interes amplios y generales. Son, en definitiva, localistas, fragmentados y parciales.

El modelo participativo es, como se analizará a continuación, sustituido por un modelo de negociación de conflictos e intereses en el cual la autoridad del ejecutivo procede a la autonomía de su mandato. Escucha los intereses, inclusive de los movimientos organizados y del partido, pero, al mismo tiempo, tiene el derecho y el deber de elegir las prioridades de gobierno en nombre de la población de la ciudad: "Tienes que tener la claridad -declaraba Erundina a mediados de 1990- de tu papel de administrador del interés público (...) el principio de autoridad tiene que ser preservado, sino quedas desacreditado delante de los propios trabajadores. (...) El mandato es de los trabajadores. El partido exagera, porque la mayoría no es afiliada. Yo creo que se tiene que administrar la ciudad, pensando en la mayoría". Y añade: "No creo que sea tarea del Estado, de la Prefeitura, tomar la iniciativa de crearlos (Los Conselhos Populares) (...) Creo que (los Plenos populares) son experiencias muy precarias ${ }^{22}$.

Estas parecen ser las bases que fundamentan el ideario de "un gobierno para todos": la participación popular exaltada en el proceso de democracia directa dejaba de ser el principio de organizador de la gestión de la ciudad. Cambia no sólo la concepción de la democracia sino el propio estilo de gobierno.

\section{INVIRTIENDO PRIORIDADES}

Hemos visto las condiciones sobre las cuales el Partido dos Trabalhadores llegó a la victoria electoral en 1988 en Sao Paulo, así como las dificultades encontradas por la nueva Prefeitura. Pasado el primer año, en la que estuvo limitada por la alta presión política originada en la campaña presidencial y por la partida presupuestaria heredada de la gestión J. Quadros, Erundina consiguió acelerar la implementación de las transformaciones en nombre de las cuales fue electa.
La acción redistributiva del estado en el ámbito del municipio, que es el principal ítem del programa petista para las administraciones locales, consiste en recoger impuestos de los que tienen más y dar beneficios a los que tienen menos. En el caso de Sao Paulo, se trata de cobrar impuestos inmobiliarios de los detentores del capital y de los habitantes de mayor renta y aplicar el dinero recogido en áreas como transportes, vivienda, salud y educación-servicios cruciales para la mayoría de la población de la ciudad.

Esto significa proceder a las dos modificaciones que afectan a los interes de las camadas más acomodadas. es necesario cobrarles más impuestos y no dar contrapartida en la forma, por ejemplo, de un mejoramiento de los servicios de tránsito, recogida de basuras, que son de su interés. El papel distributivista del poder municipal presenta, por tanto, dos caras complementarias: recaudar los recursos de forma desigual, y gastar de forma desigual.

Del conjunto de las fuentes de rentas de la Prefeitura, la única que permite una acción redistributiva en la recaudación es el impuesto directo a la propiedad inmobiliaria. Las otras fuentes de recursos no se prestan a la progresividad característica de una política tributaria que busca alterar la distribución social de la renta ${ }^{23}$. El impuesto Predial y Territorial Urbano (IPTU) al contrario, proporciona a la Prefeitura la oportunidad de discriminar los propietarios de solares y edificaciones de mayor valor y aplicarles un índice de recaudación más alto. Es por ello que sobre el IPTU recae la disputa en torno de la acción redistributiva.

En la Tabla $N^{\circ} 2$, se observa la evolución de la participación del IPTU en la estructura presupuestaria municipal. Queda claro que Erundina amplió el peso del IPTU en el conjunto de recursos del erario paulistano. La gestión petista procuró y en parte consiguió, actualizar los valores de mercado de los inmuebles y tornar progresivos su recaudación de impuestos, haciendo que el IPTU constituyese la segunda fuente de recursos de la Prefeitura. Como se podría esperar, esta medida sufre una gran resistencia por los sectores afectados ${ }^{24}$.

\begin{tabular}{|lcccc|}
\hline \multicolumn{5}{|c|}{ Tabla II } \\
Municipio de Sao Paulo \\
Participación del IPTU en la Receta Municipal \\
Años & 1989 & 1990 & 1991 & $1992 *$ \\
$\%$ & 9,7 & 10,9 & 19,1 & 20,8 \\
* estimativa & & & \\
Fuente: Secretaría Municipal de Planificación \\
\hline
\end{tabular}

22. L. Erundina: "Sem medo a ser Goberno" (entrevista), en Teoría e Deabate, $\mathrm{n}^{\circ} 11$, Sao Paulo, 1990. pp.13,14 y 15.

23. Las otras fuentes de recursos de la Prefeitura de Sao Paulo son las transferencias de los gobiernos estadual y federal, impuestos y tasas indirectos, multas de tránsito, préstamos y resultados de aplicaciones financieras.

24. Conviene recordar que el presupuesto de 1989, primer año de gobierno petista, fue realizado por la administración precedente. En relación a la progresividad del impuesto es necesario recordar que todavía es una disputa en curso; fue ampliada en los presupuestos de 1990 y 1991. La intención de ampliarla más en 1992 fue bloqueada por una acción político-judicial por parte de los grupos que se vieron perjudicados. 
Otra observación que deriva de lo expuesto es que fue recién en el tercer año de gobierno cuando la Prefeitura obtuvo un aumento significativo del IPTU. solo para 1991 el PT logró articular una propuesta de recaudación progresiva directamente vinculada a la otra cara de la política redistributiva, la del gasto, a través de un proyecto que pretendía subsidiar por completo el transporte colecivo en la ciudad. El resultado fue que, en relación a la primera propuesta presupuestaria, referente a 1990, la administración mantuvo la participación del IPTU heredada del gobierno anterior, en la segunda obtuvo un incremento considerable, prácticamente doblando el porcentaje de ese impuesto dentro del presupuesto.

Si hubo un avance claro en lo que se refiere a recaudación, también en lo que se refiere a gasto se puede constatar un aumento de lo dedicado al área social (transporte, salud, educación, bienestar social, vivienda, abastecimiento, cultura y deporte) en detrimento de otros sectores, conforme muestra la tabla 3 .

\section{Tabla III}

Gasto Social en el conjunto del Gasto de la Prefeitura.

$\begin{array}{llc}\text { Años } & \text { Administración } & \text { Porcentaje } \\ 1975-78 & \text { O. Setubal } & 32,2 \\ 1979-92 & \text { R. de Barros } & 38,4 \\ 1983-85 & \text { M. Covas } & 37,4 \\ 1986-88 & \text { J. Quadros } & 33,8 \\ 1989-91 & \text { L. Erundina } & 48,0\end{array}$

Fuentes: Balance de la Prefeitura de Sao Paulo y Relatorio mensual de Ejecución Presupuestaria.

El aumento en el gasto del área social se refleja, sobreodo, en resulados positivos en el secor de la educación, en el cual la Prefeitura es responsable de la enseñanza pública preescolar y de un tercio de la gesión de la enseñanza primaria, y en área de salud, en la cual la municipalidad controla una respetable red de hospitales y de centros de aención primaria. La acusación del gobierno petista en esos dos sectores ganó relevancia también porque fueron áreas abandonadas en la gestión anterior, caracterizada por la canalización de los recursos hacia grandes obras viarias.

La aplicación de recursos de educación permitió a la administración petista recuperar físicamente la red escolar que estaba "initulizada" por el nivel de incompetencia y negligencia con el que había sido manejada, según la descripción realizada por los nuevos dirigentes. Hubo un intenso trabajo de recuperación material de los cerca de los 600 establecimientos escolares municipales, así como el reequipamiento de los mismos. Las partidas dedicadas a esos ítems fueron de 389 \% superiores en 1991 en relación a los de 1988, incluso sobre el presupuesto heredado de Janio Quadros ${ }^{25}$.

En otras palabras, una de las principales medidas de Erundina consistió en recuperar y reaprovechar la red física de enseñanza. En segundo lugar, se procedió a una evaluación a nivel salarial de los profesionales del área. Entre 1989 y 1991 hubo un crecimiento del $40 \%$ de los gastos de personal en el sector de la educación, sin que haya habido un aumento significativo en el número de funcionarios ${ }^{26}$.

Con esas y otras medidas complementarias, algunas en el campo pedagógico, se considera que hubo una mejora significativa en las condiciones y en la calidad de la enseñanza ofrecida a los alumnos con acceso a la red municipal. En contrapartida, no hubo una ampliación sustancial del número de plazas aunque, según evaluación del propio Secretario, sea necesario doblar el número de plazas para atender la demanda existente ${ }^{27}$. La orientación que prevaleció durante la gestión del $\mathrm{P}$. es que nada se adelanta aumentando indiscriminadamente las plazas ofrecidas si la enseñanza es precaria ${ }^{28}$.

En el área de salud, hubo un gran aumento de la capacidad de atención. Según los cálculos del gobierno, hasta final de 1992 se habrían duplicado el número de camas efectivamente disponibles para la población en relación a 1988, pasando de 1.286 a $2.657^{29}$. La secretaría de salud fue la que recibió más recursos en 1991, y tuvo también una dotación comparable en 1992. A pesar de ello, según Erundina, Sao Paulo dispone apenas de 2,4 camas hospitalarias cada mil habitantes, mientras que el mínimo aceptable según la organización Mundial de la Salud es de 4 por cada mil habitantes ${ }^{30}$.

De todas formas, la canalización de recursos efectuada entre 1989 y 1992, parece haber imprimido un avance en la dirección de una política municipal capaz de atender las necesidades de educación y salud de los grupos de baja renta? Sin embargo, si esos avances requieren ser relativizados cara a la demanda, las conquisas en oras áreas, al como la vivienda, aún puede ser más el agudo déficit de la ciudad. Se calcula que, al inicio de la gestión Erundina, había un déficit de un millón de viviendas para atender las demandas de población ${ }^{31}$. Cuarenta meses después, la administración petista anunció haber construido o tener en construcción 40 mil casas, número que frente a la demanda constituye un volumen poco significativo ${ }^{32}$.

A pesar de ello, se debe considerar que construir 40 mil casas equivale a levantar una ciudad de 200 mil personas, o sea, una obra urbana de gran porte, la cual no podría haberse realizado sin una partida equivalente de recursos. Según el balance del Sempla, el presupuesto de la Secretaría de Vivienda en 1992 era el mayor que se haya

25. SEMPLA: "Avaliaçao do desempenho da açao do governo municipal” 1989/1991 (Sao Paulo: SEMPLA, 1991, p. 53).

26. Idem, p. 54.

27. Más allá de la 319 escuelas municipales de educación infantil en funcionamiento, el secretario Mario Sergio Cortella considera necesaria 500. En relación a la enseñanza primaria, el déficit sería menos grave: existen 347 y serían necesarias otras 52 escuelas. Ver Assesoria de Imprensa do gabinete da Prefeita: "Balanço Geral", Sao Paulo 1992.

28. En otras palabras, la simple apertura de nuevas escuelas en condiciones precarias de operatividad, para albergar menores mientras están sus padres trabajando, pueden interesar a los padres, pero no a los menores, y no es, por tanto, un indicador válido de desempeño. La democratización del acceso que interesa es la de una escuela pública de calidad equivalente o superior a la enseñanza privada” Ver SEMPLA, documento citado, 1991, p. 55 .

29. Idem, p.49

30. Assesoria de Imprensa do Gabinete da Prefeita 1992, p.2.

31. Idem, idem.

32. Idem, p. 6. 
destinado al área en el ámbito municipal. En otras palabras, conviene resaltar que incluso en el sector en el que la Prefeitura tuvo menos éxito frente a las grandes carencias acumuladas a lo largo de décadas, los resultados presentados no fueron despreciables, sobre todo si consideramos que de las 40 mil casas construidas o en construcción, 10 mil fueron iniciadas en la gestión Erundina y construidas sobre régimen de mutirao (autoconstrucción), destinándose directamente a núcleos de baja renta, en un programa que en las dos gestiones anteriores a la administración del PT había atendido a menos de tres mil familias ${ }^{33}$.

También la prioridad otorgada al atendimiento de los favelados, urbanizando las áreas de residencia, creció. En los dos gobiernos anteriores, cerca de seis familias fueron alcanzadas por la reurbanización de las favelas. En tres años de gobierno del PT, ese número saltó para 25 mil familias atendidas o en atención ${ }^{34}$.

En esa área es necesario señalar que tal vez la gran contribución del PT no haya sido el volúmen de cobertura de demanda, sino la forma que ella tomó. La administración incorporó los movimientos pro-vivienda en la práctica del mutirao, consiguiendo al mismo tiempo atender las antiguas reivindicaciones de esos grupos para obtener casas, y estimular el proceso democrático de organización y autogestión en los barrios.

\section{APRENDIENDO A NEGOCIAR}

"El interés público es el de los trabajadores, pero es también el interés de la población en general. (...) Yo creo que se debe administrar la ciudad pensando en la mayoría" 35. Con esas palabras, pronunciadas un año y medio después de la toma de posesión del cargo, Erundina daba señales de la rápida transformación que se operó a partir de la experiencia del poder. Fue en las disputas en torno al decisivo sector del transporte colectivo donde el cambio quedó claro en la práctica. No por casualidad fue en ese área donde se dió la mayor lucha política del período. A partir de la propuesta presupuestaria de 1991, hubo una tentativa de canalizar gran cantidad de recursos para subsidiar el transporte a los trabajadores. Lo específico de la propuesta, es que ella conectaba el enorme aumento del IPTU a un cambio radical en la política de transporte.

El ejecutivo solicitó al Legislativo municipal un aumento real del $57 \%$ en el valor del IPTU, justificando ese salto con el proyecto de subsidiar por completo el sistema de autobuses de Sao Paulo. De esta forma, el PT asociaba el uso de una tributación progresiva, como ya se vió, a la solución de aquel que había identificado en el primer año y medio de gobierno como el principal problema urbano desde el punto de vista de los sectores populares de la ciudad.

$\mathrm{La}$ "tarifa cero", como fue conocida la propuesta de viajar gratuitamente en autobus en la ciudad, sería costeada "por medio de una tasación mayor del IPTU para las grandes industrias, empresas, mansiones, grandes clubes y terrenos baldíos" ${ }^{36}$. La novedad estaba en que el PT había encontrado por primera vez una propuesta capaz de llamar la atención de la opinión pública con el objetivo de sacar a quién tiene más para dar a quién tiene menos.
Al realizar la propuesta de la "tarifa cero" asociada a un expresivo aumento del IPTU, Erundina abandonó la postura defensiva que venía caracterizando su gestión desde el inicio. La propuesta presupuestaria para 1991 dejaba claro que el proyecto redistributivo del PT atacaría el neurálgico sector de transportes, en el cual la disputa entre el sector público y el capital privado había creado, desde la década de 1950, impases que terminaban por perjudicar a los usuarios, sobre todo los sectores más pobres que utilizaban el transporte colectivo.

La tramitación de la propuesta en el Legislativo municipal fue demostrativa del tipo de resistencia, de los límites, pero también de alternativas que el gobierno petista encontró para llevar a buen término una política redistributiva. La estrategia utilizada por el ejecutivo fue la de procurar movilizar a la población contra los vereadores de la oposición, de manera que éstos se viesen obligados, por presión popular, a votar favorablemente por el aumento del impuesto y la eliminación de las tarifas de autobus. La estrategia fracaso, una vez que, a pesar de ser beneficiosa para los sectores pauperizados de la ciudad, la "tarifa cero" no consiguió despertar un movimiento a su favor. La tentativa de aislar a los vereadores contrarios a la propuesta no dió el resultados esperado y obligó al ejecutivo, que no disponía de mayoría en la Cámara, a abandonar la "tarifa cero" ya que no sería aprobada.

Mientras tanto, el hecho de haber tomado finalmente la iniciativa política dejó un saldo positivo. Entre otras cosas, permitió a la Prefeitura negociar con la Cámara un aumento real del IPTU del orden del $125 \%$, lo que se reflejaría en un expresivo aumento de la participación de este impuesto en el presupuesto de 1991, lo que posibilitó, con los recursos recaudados por esta vía, proseguir con mayor vigor en las inversiones sociales a partir de aquel año. Después de todo, la fracasada propuesta de la "tarifa cero" terminó abriendo la puerta para que cerca de un año más tarde vino a ser la municipalización del transporte colectivo de la capital, tal vez la realización más visible de toda la gestión Erundina.

La municipalización, aprobada en septiembre de 1991, fue una alternativa menos radical del punto de vista distributivista de lo que hubiera sido la tarifa cero, pero significó un avance muy considerable en lo que se refiere dos tópicos claves en la cuestión de los transportes. De un lado, aumentó acentuadamente el control del poder público sobre el servicio. De otro, representó una posibilidad de mejora en la calidad del sistema, sin aumento de la tarifa para el usuario. De acuerdo con las espectativas oficiales, la municipalización permitiría una ampliación de la flota en 2.000 autobuses hasta final de $1992^{37}$.

33. Datos comparativos facilitados por la División Técnica de Planificación de la Superintendencia de Vivienda Popular, SEHAB.

34. Idem

35. L. Erundina, op.cit., pp. 13-14

36. L. Erundina: "Quarenta meses de trabajo" en Shopping News, Sao Paulo, 24/05/1992.

37. Ver Sempla, 1992. Esta ampliación significa un crecimiento del $25 \%$ de la flota. Notese que el número de autobuses de Sao Paulo era el mismo desde 1977. Con el aumento de la flota, una de las metas de la 
La municipalización fue el resultado más nítido de la política de negociación emprendida por la gestión Erundina junto al empresariado y al poder legislativo a partir del fracaso de la "Tarifa Cero". Ella no se habría realizado si el Ejecutivo municipal no se hubiese empeñado profunda y pacientemente en llegar a un acuerdo que no fuese de suma cero junto a los episodios de la "tarifa cero" y de su desdoblamiento en la municipalización, son así simbólicos del tipo de trayectoria política que los petistas realizaron al frente del gobierno.

Al asumir la Prefeitura, Erundina insistía en la propuesta de estatizar el transporte colectivo, lo que significaría eliminar la iniciativa privada del sector. Es sintomático el cambio petista en la declaración del líder del gobierno legislativo local en la época de la municipalización, el concejal Francisco Whitaker: "No hay condición ninguna de resolver la situación del transporte sin los empresarios" ${ }^{38}$

El cambio de postura en relación al empresariado está reflejada, a su vez, en una entrevista de la prefeita realizada en 1990: Reportero -"La señora ahora negocia directamnte con empresarios poderosos. ¿Su juego de cintura es ahora mayor?" Erundina- "No sólo es juego de cintura. Creo que es una relación más realista, sin mitos ni prejuicios, y de ambos lados. Pienso que existían prejuicios de los empresarios hacia mi persona y viceversa. En los primeros encuentros, ciertamente hubo mucho más ansiedad por parte de ellos, que me imaginaban una incendiaria y que iría a hacer el socialismo en la ciudad de Sao Paulo, pero yo misma sabía que no iba a hacer nada de eso. Mi trato con ellos ha sido positivo, sin que tenga que hacer concesiones en mis principios. Yo siempre les digo: "Mire, ustedes le deben a la ciudad la mano de obra barata que pagan, los servicios públicos que los benefician". Hemos tenido una relación franca y honesta, siempre en el interés de la ciudad, y ellos han sido sensibles" ${ }^{39}$.

Una expresión más teórica de este cambio de postura puede encontrarse en las posiciones asumidas por el Secretario de Planificación, Paul Singer, cuya exposición al respecto vale la pena citar in extenso: "La izquierda en el Poder Ejecutivo Municipal puede y debe (en función de sus compromisos de clase) dirigir la ciudad dando prioridad a los intereses de las clases populares. Pero sólo puede hacer esto contando con la colaboración de las clases dominantes, cuyos intereses no son priorizados pero tampoco pueden ser negados o ignorados. Interesa a los sectores populares que el capital privado permanezca y se acumule en la ciudad; que los concesionarios de servicios públicos En Sao Paulo, por ejemplo, empresas de autobuses, recogida de basuras, de barrido de paseos, etc.-, invierten en la mejoría de la calidad y en la expansión de los mismos; y que las constructoras de obras públicas y los proveedores de la administración inviertan para aumentar la productividad y la eficacia de las empresas.

"Cabe evidentemente a una administración municipal popular y democrática impedir que los concesionarios, constructoras y proveedores tengan beneficios exagerados, por encima de lo normalmente estipulado (...). Pero sería un error, del cual resultarían perjudicados para los sectores populares, suponer que los referidos lucros tendrían que ser minimizados o eliminados. La gestión democrática y popular de S. Paulo aprendió esta lección en el inicio de su mandato $(\ldots)^{40}$.

Como se puede desprender de las exposiciones citadas, la práctica mostró a los administradores petistas que la reversión de las prioridades no podría ser realizada sin una negociación con los detontores del capital y sus representantes políticos. Esta fue la primera lección práctica del gobierno: la de que no es posible desconocer los interes de la minoría, aunque sea posible contenerlo en beneficio de la mayoría, en la medida en que se disponga de fuerza política para ello.

Cabe señalar, que el aprendizaje de la administración no siempre fue acompañado por el partido, que en muchos momentos se convirtió en un elemento de resistencia a la trayectoria del gobierno. El tono de las críticas de la dirección del PT puede ser sentido por el siguiente pasaje del documento de evaluación del primer año de gobierno: "(...) No conseguimos producir acciones de mayor repercusión pública contra los sectores empresariales que se apropian del espacio urbano y de la explotación de los servicios públicos en detrimento de los intereses de la gran mayoría de la población como los especuladores inmobiliarios y los dueños de las empresas de autobuses" ${ }^{41}$.

A pesar de ello, el proceso de transformación del gobierno no cesó. Una segunda lección aprendida por los Petistas en la administración es que los intereses de la mayoría no son homogéneos. En las palabras de Singer, "la mayoría es una suma de minorías" ${ }^{42}$, lo que obliga una administración que se pretenda representante de la mayoría a ser mediadora de los conflictos que se oponen entre sî los varios segmentos de esa misma mayoría.

La elección del sector de transportes como prioridad del gobierno petista corresponde a una trayectoria sintomática de la administración también en este sentido Antigua militante del movimiento por la vivienda, Erundina se benefició del apoyo de ese sector, que está entre los más organizados de la capital, en la elección de 1988. Se

Secretaría de Transportes era reducir de 11 a 7 el número de pasajeros por metro cuadrado Municipalización significa el control del poder público sobre el sistema de transporte en la ciudad, sin que con ello se elimine al capital privado que, sin embargo, pasa a estar subordinado a la Prefeitura. Así, la recaudación procedente del cobro de billetes es concentrada en una caja única municipal, que paga a las empresas contratadas por el servicio prestado, en la base del $80 \%$ correspondiente al kilometraje rodado y $20 \%$ al número de pasajeros efectivamente transportados. Con ese sistema, de un lado la propia CMTC (empresa municipal de transportes) puede racionalizar su propia operatividad $y$, por otro, hay un estímulo para que las empresas privadas aumenten la flota y dejen de sobrecargar los autobuses, ya que ganan por kilometraje, independientemente del número de pasajeros transportados.

38. Declaración realizada a investigadores del Centro de Estudos de cultura Contemporanea (CEDEC), en entrevista realizada en septiembre de 1991. Ver F. Abruccio: “A tomada de decisao no parlamento paulistano dentro da nova ordem democrática: o caso da municipalizaçao do sistema de onibus urbano", (Sao Paulo: CEDEC - working paper 99/90, 1991, p. 33).

39. L. Erundina, op. cit, 1990 (????).

40. P. Singer: "Participaçao popular na administraçao de Sao Paulo”, Informe Interno del PT,1992,pp.8 - 9.

41. Directorio Municipal PT-Sao Paulo, documento citado, 1991, p. 3.

42. F. Abruccio, op.cit, 1991, p. 26. 
esperaba, por tanto, que el problema de la vivienda fuese a ocupar el centro de la atención de la nueva prefeita. Sin embargo, no fue esto lo que acontenció. Rápidamente la administración asumió una postura de gobernar "para todos” y dejó de beneficiar a las facciones más organizadas del movimiento popular.

En la época que se lanzó la "tarifa cero", el gobierno municipal había concluido que la mayor carencia de la población de Sao Paulo era el transporte. A partir de ahí, dió al transporte colectivo la primacía dentro de los innumerables problemas que afectan a la población pobre, ya que éste parecía ser el problema más general.

Tres aspectos relativos a los movimientos populares pueden haber contribuido a que hubiese este cambio en la práctica, aunque no sea asumido en el plano del discurso. El primero fue la constatación de que los movimientos organizados representan apenas una parcela bastante minoritaria de la población, más allá de que algunos de ellos cuenten con una amplia legitimidad y enraizamiento, como los movimientos de la vivienda y la salud.

Se verificó en la práctica que un vasto contigente de habitantes de la ciudad o está fuera de cualquier tipo de organización o continúa vinculado a esquemas clientelístas de representación política. Al poco tiempo, la administración percibió que precisaba adoptar estrategias amplias, volcadas para el gran número de ciudadanos que se encuentra fuera de los movimientos populares organizados. Frente a esta necesidad, el peso decisorio de los movimientos organizados se redujo.

El segundo aspecto es que la heterogeneidad de los movimientos sociales dificultó el encuentro de formas de deliberación conjunta que representasen los preceptos democráticos. Cada movimiento representa grupos numéricamente desiguales de ciudadanos y escoge sus delegados de acuerdo con criterios definidos internamente. De esta manera, una organización que congrega, por ejemplo, 10 mil familias "sin techo" se tiene que sentar a decidir junto a otra que congrega a cien familias de favelados. En este caso, cada una de las organizaciones tendría derecho a un voto, conformando una situación de absoluta desproporcionalidad. Al no encontrar soluciones para este tipo de problemas, los mecanismos de decisión colectiva se vaciaron de contenidos, aunque la administración haya consolidado algunos canales de consulta junto a los movimientos populares, por ejemplo en la elaboración del presupuesto. Esa práctica, cuyo valor no debe ser despreciado, quedó sin el desarrollo imaginado en el inicio del mandato.

El tercer obstaculo al desarrollo de la participación directa, como se señaló anteriormente, lo constituyó la verificación de que en la acción concreta los intereses particulares de cada movimiento prevalecía sobre los intereses generales de la sociedad. Detrás de una capa más o menos ideologizada, había una presión para que se atendiese los objetivos específicos de cada sector, sin consideraciones por las consecuencias más amplias de las decisiones reivindicadas. Esa realidad produjo aquellos que algunos participantes de tales procesos vendrían a llamar “clientelismo de izquierda".
El "clientelismo de izquierda" consiste en la utilización de mecanismos diversos, que van desde el contacto directo y privilegiado de algunos movimientos con sectores de la administración, pasando por encima de la instancias participativas, hasta la acción de veradores del PT como enlaces con el gobierno municipal de los intereses específicos de los grupos organizados que lo eligieron. "En realidad continua una relación clientelista. Hay clientelismo en el PT, de los vereadores que representan los movimientos o bases territoriales que vienen a intermediar la relación entre sus bases y el Ejecutivo, como una especie de despachante (...)" ${ }^{43}$.

En contrapunto a las dificultades participativas, otra práctica de negociación, involucrando tanto al capital como a los trabajadores, acabó teniendo éxito. Sin abandonar la noción de que la participación directa puede significar un complemento importante al funcionamiento de la democracia representativa, la gestión petista se volcó en la creación de cámaras de negociación entre los grupos sociales en conflicto, en los cuales procuró actuar como mediadora en busca de soluciones que fuesen de suma cero, a ejemplo de lo que había acontecido en el caso de la municipalización de los transportes.

Se crearon innumnerables foros de negociación, entre los que se destacan los relativos a las tarifas de recogidas de basura, de autobuses, la revisión de la Planta Genérica de valores, la localización del comercio ambulante, el Plano Director de la Ciudad congregando representantes de empresarios, de sindicatos de trabajadores, de movimientos populares, de la llamada sociedad civil y de órganos técnicos. Tales instancias fueron la respuesta participativa a la necesidad de establecer al mismo tiempo negociaciones con los detentores del capital y los varios segmentos de trabajadores involucrados en los problemas en liza.

Por medio de los consejos de negociación, el gobierno Erundina configuró una nueva forma de relacionarse con los sectores importantes de la sociedad, como son los empresarios, la representación sindical de los trabajadores, los movimientos populares y incluso el poder Legislativo. Un aprendizaje análogo emergió de la conflictiva relación entre el propio PT y el gobierno. La administración percibió que gobernar "para todos" significaba diferenciarse del partido, que por definición, es una parte de ese todo ${ }^{44}$. A partir de entonces, el PT se tranformó en una instancia más de poder con la cual sería necesario negociar para adoptar políticas como respaldo. Una vez más, fue la creación de una instancia permanente de negociación que permitió a la administración escapar de los impases a la que el enfrentamiento entre ella y el PT apuntaron en reiteradas ocasiones.

43. Entrevista realizada en 1990 con un militante del partido que ocupa un alto cargo de la administración municipal de Sao Paulo.

44. P. Singer, op.cit., 1990, pp. 2 - 3. "Es preciso asumir la duplicidad del mandato representativo y no procurar eludirla. La Prefeita de sao Paulo, en tanto petista, no pude dejar de ori al partido por medio de sus instancias no desconsiderar las opiniones de las mismas. Pero la Prefeita de sao Paulo, en cuanto representante de la mayoría electoral, tiene la obligación de actura de acuerdo de la mayoría electoral, tiene la obligación de actuar de acuerdo con su conciencia de lo que ella considera como mejor para los intereses de los trabajadores de la Capital". 
Como ya se ha señalado, frente a las dificultades de enfrentar crisis más profundas, es convocada una Plenaria para ecuacionar las relaciones entre partido y el ejecutivo municipal. La voluntad política de entendimiento da origen a un forum en el cual, además de la Prefeita y de algunos de sus asesores, tiene asiento el secretario, el presidente y el portavoz del grupo parlamentario petista de los niveles municipal, estadual, y federal. Esto significa que el Partido de los Trabalhadores, no solo el PT del municipio, se hizo presente en las discusiones de los problemas estratégicos de la administración de la ciudad. Preservada la autonomía de las instancias decisorias y la iniciativa política del gobierno, se debatía en conjuntoalternativas de respuestas a los ataques del Tribunal de Cuentas al Ejecutivo municipal, la huelga de conductores de autobuses o la campaña del candidato del Pt a la Prefeitura de sao Paulo en 1992. Sin negar una situación que continua muchas veces extramadamente tensa, es necesario afirmar que los conflictos y debates entre Administración y $\mathrm{Pt}$ adquirieron mayor fluidez, al mismo tiempo que el campo de negociación ganó un amplio aspectro de legitimidad.

Al mismo tiempo, basicamente a partir de 1991, las transformaciones político-ideológicas irían a dar un nuevo contorno a las bases de sustentación del gobierno municipal. esto es así por varias razones, entre las que destacan la postura mencionada de negociación, y el posicionamiento frente a las huelgas de funcionarios municipales, ciertas tendencias internas del PT pasaron a oponerse a lo que denominan de "política de conciliación" o inclusio "traición de clases” de Erundina ; otras, a su vez dieron origen a un nuevo conglomerado político, que iría a convertirse en uno de los pilares básicos de la Prefeitura: No es cuestión de detallar aquí la geografía de las fuerzas que constituyen la base de su sustentación política, pero es preciso dejar en claro que la fase final del mandato es bien distinta de la de los periodos iniciales de la administración Luiza Erundina ${ }^{45}$.

\section{CONSIDERACIONES FINALES: SOBRE LA RESPONSABILIDAD POLÍTICA}

Si es que hay cabida para un resumen del análisis de una experiencia recién concluida, vale la pena inicialmente fijar dos puntos. de un lado, el gobierno Erundina mostró que la inversión de prioridades no es una quimera, y que una administración volcada en los intereses populares puede promover una distribución de la renta, con beneficios para grupos menos favorecidos de la sociedad. Por otro lado, la experiencia política frente a la Prefeitura parece indicar que en la medida en que se amplió la capacidad de negociación y mediación de los conflictos urbanos que enfrentan a capitalistas y trabajadores, así como los trabajadores entre sí, la administración fue capaz de invertir prioridades. La pregunta que queda es si la experiencia apunta hacia la construcción de una nueva forma de ecuacionar la práctica de gobierno, o si solo quedará como registro de los cuatro años de gobierno en que una mujer "nordestina y socialista", como a ella le gusta autodefinirse, gobernó la principal ciudad del país.
En este sentido, parece oportuno destacar la gestión del PT frente a la Prefeitura de Sao Paulo se articula sobre una aparente contradicción. Un partido que llega al poder municipal para realizar una plataforma clasista, termina por redescubrir valores tan poco "ortodoxos" como la moralidad pública, gobierno como representación de todos los habitantes, rescate de la noción de ciudadanía y la negociación política.

Sería, por tanto, un error considerar que la trayectoria petista en sao Paulo consiste en un abandono de los propios principios o la abdicación del objetivo fundamental de revertir prioridades para atender a las mayorías desasistidas de la ciudad. También sería un equívoco no percibir que la voluntad democrática que estaba en la base del programa paricipativo original fue el motor de la construcción de los consejos y cámaras de negociación que, en cierta medida, terminaron por convertirse en el punto fuerte de la administración.

En realidad, la gestión del PT acabó por ser una mezcla peculiar de sus características basistas -con todo aquello que el basismo tiene de radicalmente democrático y, al mismo tiempo, autoritario-y las condiciones reales de la práctica política en el Brasil de los 80 y comienzo de los 90. En ese contexto, la administración petista destacó positivamente por la transpariencia en el trato de los negocios públicos, por la capacidad de utilizar el espacio institucional para poner en funcionamiento medidas distributivas, sin darles el carácter populista tradicional que han tenido en la política brasileña, y por una concepción de la negociación como instrumento principal para oponerse al Estado al servicio de los intereses de la mayoría de la población. Concepción, ciertamente, democrática y, según todo parece indicar, también moderna.

Tal vez la principal marca negativa del gobierno hay sido una cierta falta de iniciativa, reflejada en la dificultad de articular el prceso administrativo a la lucha política más general. Esta es la crítica más fuerte de una parcela considerable del PT, sobre todos del aparato, a lo que han llamado “administrativismo" o "legalismo" de la gestión petista de Sao Paulo.

Es cierto que las oscilaciones iniciales dificultaron, como intentamos mostrar en lo dicho anteriormente, la puesta en marcha de reformas distributivas, que están en la médula de la propuesta petista. Quién sabe si el camino que una iniciativa política y negociación hubiese sido descubierto antes, la andadura de la administración podría haberse acelerado tanto en lo que atañe a las realizaciones oncretas como en los términos de consolidar nuevas formas de gobernar.

Pero la verdad es que el PT tuvo en Sao Paulo, donde se concentran el tercer presupuesto del Estado Brasileño y alrededor de 150.000 funcionarios, su más compleja

45. Los grupos Troskistas que continúan en el PT, en reiteradas ocasiones, pasaron a hacer oposición a la gestión de Luiza Erundina. Se destaca, por otro lado, el "proyecto para o Brasil" -agrupamiento originado de una cesión de la tendencias "Nova Esquerda" y de "Vertiente Socialista" (ver nota 2), a la que se sumó "PT Vivo", este último con varios cargos importantes en la máquina administrativa municipal- como principal apoyo de la administración. 
escuela de gobierno, la experiencia concreta de intentar realizar una plataforma enfrentando la realidad de una población cuya mayoría se empobreció gravemente a lo largo de los 80 .

El fruto de esa experiencia es la construcción, necesariamente lenta y oscilante, de aquello que se ha denominado "el modo petista de gobernar". En pleno proceso de gestación, este expresa, por un lado, un ideario de tradición republicana que insiste no sólo en la eficacia de la máquina gubernamental y en la calidad de los servicios, sino, sobretodo, en la transparencia y lisura administrativa $y$, en la consecuente separación de esferas de intereses privados y públicos. A partir de aquí, esta tradición de acción y pensamiento se vuelve también democrática porque enfatiza la necesidad de control permanente de la sociedad civil sobre los aparatos decisorios del Estado.

Por otro lado, "el modo petista de gobernar" parece apoyarse al menos en cuatro proposiciones estratégicas. Prevalece una concepción de democracia que combina representación política y participación directa con el empeño de desprivatizar o tornar público lo que es estatal ${ }^{46}$. A lo que se une la postura de negociación de conflictos que lejos de basarse en una concepción de universalidad supuestamente neutra, procura constituir las alianzas políticas que permiten realizar la inversión de prioridades del gobierno de inmediato, se trata de intentar una creciente reedistribución y transferencia de renta en favor de los habitantes pobres y, a largo plazo, impulsar un cambio en la apropiación de los beneficios materiales y culturales de la ciudad, pues está entendida como un territorio que refleja las luchas de los sectores y clases con intereses divergentes e incluso antagónicos. Lo básico de este proyecto de sociedad es la preponderancia del reconocimiento de la diversidad en todas sus manifestaciones, inclusive el reconocimiento de esta concepción de la democracia que el PT procura construir su concepción de socialismo ${ }^{47}$.
No hay duda que la administración del PT en Sao Paulo avanzó en algunos de los puntos mencionados, mientras que en otros no pasaron de argumentos para la creación de un discurso político alternativo. De todas formas, es posible afirmar que, si la construcción del Partido dos Trabalhadores procede inicialmente de las vinculaciones con los movimientos sindicales y populares, y de la acción parlamentaria, actualmente ella alcanza nuevas dimensiones políticas a partir de la experiencia acumulada en el gobierno de las ciudades.

En este sentido, la gestión de Luiza Erundina fue de vital importancia para las varias redefiniciones programáticas del PT en el ámbito nacional. Tal vez ese gobierno se encuadre más en aquello que fue denominado republicanismo democrático, cuya experiencia no haya sido alimentada por una concepción estricta senso clasista. Con todo, teniendo en cuenta las prácticas privativistas y el clientelismo imperantes en las relaciones de poder en Brasil, hay que preguntarse si esto no contiene una posibilidad de transformación ética y política profunda. Después de todo, la responsabilidad en el trato de la Cosa Pública es un elemento nada despreciable para el enraizamiento de una cultura democrática y para la propia democratización del Estado y de la sociedad.

46. Los grupos Troskistas que continúan en el PT, en reiteradas ocasiones, pasaron a hacer oposición a la gestión de Luiza Erundina. Se destaca, por otro lado, el "proyecto para o Brasil" -agrupamiento originado de una cesión de la tendencias "Nova Esquerda" y de "Vertiente Socialista" (ver nota 2), a la que se sumó "PT Vivo", este último con varios cargos importantes en la máquina administrativa municipal- como principal apoyo de la administración.

47. Ver Partido dos Trabalhadores: resoluçoes do $1^{\circ}$ Congresso do PT (Directorio Nacional do PT, 1992. pp. 32-33).

\section{RESUMEN}

En este artículo, Lucio Kowarick y André Singer analizan la gestión del Partido dos Trabalhadores en la Alcaldía de Sao Paulo encabezada por Luiza Erundina. Con esta evaluación pretenden conocer la acción del PT a través de uno de sus principales elementos de construcción del PT, el gobierno de las ciudades, que complementa a los otros dos, la vinculación con los movimientos sindicales y populares y la acción parlamentaria.

\section{ABSTRACT}

In this article, Lucio Kowarick and Andre Singer analyses the government of Sao Paulo by Partido dos Trabalhadores, with Luiza Erundina. With this evaluation, they try to know the action of PT through one of the main elements of contruction of PT, the government of cities. The other are links with trade unions and popular movements and parliamentarian action. 